\title{
Interactive effect of cognitive function and intervention on the walking independence of stroke patients: a retrospective cohort study
}

\author{
Takuya Umehara ${ }^{1, *}$, Miwako Tsunematsu2 ${ }^{2}$, Katsunori Sugihara ${ }^{3}$, Kaori Yata4 ${ }^{4}$, Masayuki Kakehashi ${ }^{2}$ \\ 'Department of Rehabilitation, Faculty of Rehabilitation, Hiroshima International University, Hiroshima, Japan \\ 2Department of Health Informatics, Graduate School of Biomedical and Health Sciences, Hiroshima University, Hiroshima, Japan \\ ${ }^{3}$ Department of Rehabilitation, Hiroshima City Rehabilitation Hospital, Hiroshima, Japan \\ ${ }^{4}$ Department of Rehabilitation Technology, Hiroshima City Rehabilitation Hospital, Hiroshima, Japan
}

The purpose of this study was to investigate the interactive effect of cognitive function and intervention on walking independence of stroke patients. Stroke patients $(n=405)$ who admitted to convalescent rehabilitation ward, were classified as being walking independent or dependent. To examine the interaction between cognitive function and intervention, high cognitive function (functional independence measure score $\geq 20$ ) and physical therapy and occupational therapy intervention delivered in 1 day (lasting $>2 \mathrm{hr}$ ) were defined as cognition-intervention interaction and included as independent variables. The incidence of walking independence was calculated using Kaplan-Meier curves. Intergroup differences were estimated using log-rank test. Cox proportional hazards analysis was used to extract the predictors of walking independence. Survival analyses using Kaplan-Meier log-rank test showed that the probability of incidence of walking independence was significantly higher in the presence of a cognition-intervention interaction. The results of Cox proportional hazards analysis showed that age, left versus right cerebral damage, and cognition-intervention interaction significantly influenced walking independence at discharge from the hospital. The hazard ratios were 0.971 per year of age, 0.544 for left versus right cerebral damage, and 1.794 for cognition-intervention interaction. Walking independence was more likely to be achieved by stroke patients with high cognitive function who received therapy. In other words, the conditions that increase the likelihood of an effect of therapy intervention on walking independence were identified in this study.

Keywords: Cognition-intervention interaction, Elderly, Rehabilitation, Stroke, Walking independence

\section{INTRODUCTION}

The recovery of independent walking is one of the most important components of quality of life in individuals with stroke. It is also the component to which physical therapists can primarily contribute. In 2014, the number of stroke patients hospitalized in Japan was reported to be 1,179,000 (Ministry of Health, Labor and Welfare, 2014b). The proportion of patients treated for stroke is the second largest in Japan (Ministry of Health, Labor and Welfare, 2014a). Almost two-thirds of stroke survivors have initial mobility deficits (Jørgensen et al., 1995; Shaughnessy et al., 2005), and 6 months after a stroke, more than $30 \%$ of survivors remain unable to walk independently (Jørgensen et al., 1995; Mayo et al., 2002; Patel et al., 2000). Therefore, physical therapists are required for prompt recovery of walking ability of stroke patients.

The population of Japan is aging rapidly. In 2015, the proportion of population aged $\geq 65$ years was as high as $26.0 \%$ and that aged $>75$ years was $12.5 \%$ (Ministry of Health, Labor and Welfare, 2015); by 2025, the former is estimated to increase to $28.7 \%$ and the latter to $16.7 \%$ (Ministry of Health, Labor and Welfare, 2015). The proportion of stroke patients is also anticipated to increase simultaneously. Another serious challenge posed by the ag-
${ }^{*}$ Corresponding author: Takuya Umehara (i) https://orcid.org/0000-0002-2019-2914 Department of Rehabilitation, Faculty of Rehabilitation, Hiroshima International University Kurose-Gakuendai 555-36, Higashi-Hiroshima, Hiroshima, Japan E-mail: start.ume0421@gmail.com

Received: May 1, 2020 / Accepted: May 16, 2020
This is an Open Access article distributed under the terms of the Creative Commons Attribution Non-Commercial License (https://creativecommons.org/licenses/by-nc/4.0/) which permits unrestricted non-commercial use, distribution, and reproduction in any medium, provided the original work is properly cited. 
ing population and stroke were the increased number of people with cognitive function decline. Cognitive dysfunction at admission was associated with functional recovery in stroke patients (Mutai et al., 2012). Declining cognitive function is known to hinder walking independence (Stolze et al., 2005). Given the high prevalence of dementia, it is important to consider the improvement of walking ability of stroke patients in relation to the deterioration of cognitive function and stroke to predict the recovery of functional mobility (Ozdemir et al., 2001; Park et al., 2017).

Various factors related to walking independence of stroke patients have been reported so far; these include age, sex, disease type, National Institutes of Health Stroke Scale score, disorders of consciousness, motor paralysis, sensory disorder, presence/absence of cognitive impairment, upper- and lower-limb functions, and sitting function (Duarte et al., 2010; Veerbeek et al., 2011). There is also evidence that the 6-month walking ability of stroke patients is affected by activities of daily living before stroke onset (SánchezBlanco et al., 1999). In addition, exercise therapy provided by physical therapy and occupational therapists is effective in recovering function and walking ability after stroke (Jørgensen et al., 1995; Shaughnessy et al., 2005). Hiraoka et al. (2017) reported that improved neurological symptoms and cognitive function are necessary conditions for walking independence approximately 1 month after stroke onset. Although many factors are known to influence the walking independence of stroke patients, little is known about whether the influence is independent or there is interaction between the factors.

Therefore, the purpose of this study was to investigate the interactive effect of cognitive function and intervention on walking independence of stroke patients. This study aimed to provide important information on the conditions and the critical intervention that make the interventions effective.

\section{MATERIALS AND METHODS}

The design of this study was a retrospective cohort study and was approved by the Ethics Review Committee (approval number: E-629-1). The methods followed were somewhat consistent with those of Umehara et al. (2018). This study was performed in accordance with STROBE (STrengthening the Reporting of OBservational studies in Epidemiology) statement. Medical records were collected from patients hospitalized between April 2013 and March 2016. All patients were Japanese and had hemorrhage or cerebral infarction recorded in the patient database. Patients were excluded if they met the following exclusion criteria: (a) patients were transferred to an emergency hospital because of complications, which needed intensive care and (b) patients could not walk independently before cerebrovascular event. In addition, patients who had experienced subarachnoid hemorrhage were excluded, because subarachnoid hemorrhage has a worse prognosis than cerebral infarction or hemorrhage (Yoshimoto et al., 1995).

Interventions, which were tailored to patient conditions, were conducted by physical, occupational, and speech-language-hearing therapists accordance with the direction of a doctor. Physical therapy interventions focused on improvement of functional impairments and basic activities of daily living. Occupational therapy interventions focused on improvement of disability and instrumental activities of daily living. Speech therapy interventions focused on improvement of language function and swallowing function as well as communication disorders. Hospital length of stay was reviewed by the attending therapist and doctor.

Basic medical information, intervention for each type of therapy, and activities of daily living were evaluated. Basic medical information included sex, age, period until admission, length of stay, presence or absence of higher brain dysfunction, and body mass index. Intervention for each type of therapy was defined as the duration (in hours) of physical therapy, occupational therapy, and speech therapy received by each patient. Activities of daily living were measured using modified Rankin Scale and functional independence measure scores at admission and discharge. Patient information was extracted from medical records. The number of hours of physical therapy, occupational therapy, and speech therapy were extracted from medical records. The modified Rankin Scale scores reflect patients' perception of functioning within the context of their lives and potentially offer a meaningful assessment of global poststroke functional recovery, in which each grade describes patient status (van Swieten et al., 1988). Individual scores in the modified Rankin Scale describe clinically distinct functional states of the patients. The walking ability was judged using functional independence measure, which is a widely used tool for evaluating stroke rehabilitation. Functional independence measure helps evaluate motor function and cognition and reflects actual activities of daily living capability (Mosselman et al., 2013). For the functional independence measure assessment, the activities of daily living that the patients were "doing" at the time of admission and discharge were extracted by the face-to-face method from nurses. The validity of the results of the functional independence measure assessment was confirmed by a conference involving physicians, assigned physical therapist, occupational therapist, speech therapist, and nurses. The highest and the lowest to- 
tal scores are 126 and 18, respectively. Functional independence measure consists of two components: motor and cognition. To determine functional independence measure motor score (functional independence measure-motor), the 13 items were assessed on a 7-point scale (where $1=$ total assistance and $7=$ complete independence). To determine functional independence measure-cognition score (functional independence measure-cognition), the following five items were assessed on a similar 7-point scale: comprehension, expression, social interaction, problem solving, and memory. Typically, the total scores obtained for the functional independence measure-motor (ranging from 13 to 91 ) and functional independence measure-cognition (ranging from 5 to 35) components are used to evaluate functional independence regarding activities of daily living.

The incidence of walking independence was calculated using Kaplan-Meier curves. Intergroup differences were estimated using log-rank test. Cox proportional hazards analysis was used to extract the predictors of walking independence. Walking dependence was defined as a score on the functional independence measure walking item $\leq 5$, whereas walking independence was defined as a score $\geq 6$ (Mosselman et al., 2013). Furthermore, Cox proportional hazards analysis was used to examine the association between functional independence measure $\geq 6$ (scored as 1 ) and functional independence measure $\leq 5$ (scored as 0 ). Adjusted hazard ratios for the incidence of disability with $95 \%$ confidence intervals were estimated. When the correlation coefficients between independent variables exceeded 0.8 , the more clinically important variables were adopted to account for multicollinearity. Only the intervention delivered by each therapist was considered for higher correlation coefficients. To examine the interaction between cognitive function and intervention, high cognitive function (functional independence measure-cognition $\geq 20$ ) and physical therapy and occupational therapy intervention delivered in 1 day (lasting $>2 \mathrm{hr}$ )

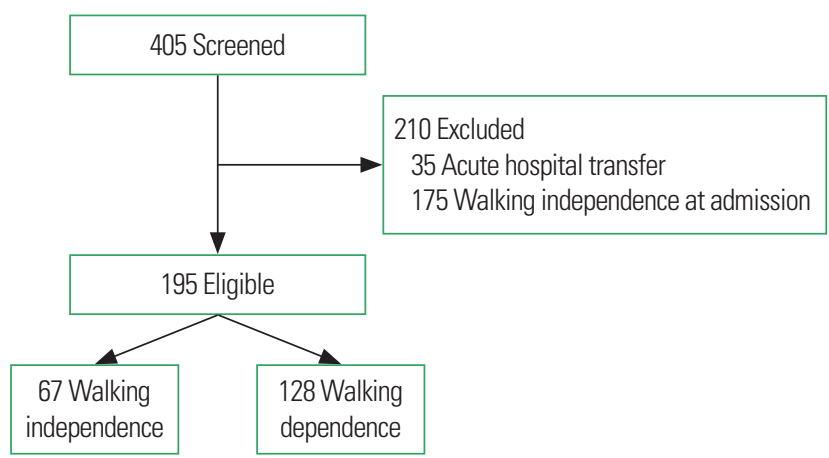

Fig. 1. Flow of stroke patients through the study. were defined median value as cognition-intervention interaction and included as independent variables. IBM SPSS Statistics 23.0 for Windows (IBM Corp., Armonk, NY, USA) was used for analyses. For all tests, a $P<0.05$ was considered statistical significance.

\section{RESULTS}

An illustration of patient flow through the study is provided in Fig. 1. Of the 405 patients who completed a baseline assessment between April 2013 and March 2016, individuals were excluded from further analyses for the following reasons: 35 patients were transferred to an acute hospital due to complications, and 175 patients who walking was independence at the time of admission. The remaining 195 patients (mean age, $70.7 \pm 12.7$ years; $47.2 \%$ women) were included in the analyses (Table 1).

Fig. 2 shows Kaplan-Meier curves indicating the cumulative incidence of walking independence following stroke. Survival analyses using Kaplan-Meier log-rank test showed a significantly high probability of incidence of walking independence in the presence of a cognition-intervention interaction $(P<0.001)$.

Cox proportional hazards analysis was used to determine associations between walking independence and intervention (Table 2). The mean period until walking independence was achieved was $111.6 \pm 43.6$ days. Overall, 67 patients achieved walking independence at discharge (Fig. 1). Correlation analysis between the walking independent and dependent groups revealed the following variables for inclusion in the Cox proportional hazards model: sex, age, presence of cerebral infarction or hemorrhage, presence or absence of higher brain dysfunction, physical therapy and occupa-

Table 1. Basic attributes, medical attributes, and activities of daily living among patients categorized into independence and dependence walking groups

\begin{tabular}{lccc}
\hline Variable & $\begin{array}{c}\text { Walking } \\
\text { independence } \\
(\mathrm{n}=67)\end{array}$ & $\begin{array}{c}\text { Walking } \\
\text { dependence } \\
(\mathrm{n}=128)\end{array}$ & $P$-value \\
\hline Gender & 39 & 64 & 0.294 \\
$\quad$ Male & 28 & 64 & \\
$\quad$ Female & $64.5 \pm 13.1$ & $73.8 \pm 11.5$ & 0.000 \\
Age (yr) & $32.2 \pm 12.3$ & $36.1 \pm 13.9$ & 0.051 \\
Period to admission (day) & $133.7 \pm 35.4$ & $125.8 \pm 40.4$ & 0.157 \\
Length of stay (day) & $22.3 \pm 3.2$ & $21.0 \pm 3.0$ & 0.007 \\
Body Mass Index (kg/m $\left./ \mathrm{m}^{2}\right)$ & 37 & & \\
Location of cerebral damage & 30 & 61 & 0.366 \\
Left & & 67 & \\
Right & & & \\
\hline
\end{tabular}

(Continued to the next page) 
Table 1. Continued

\begin{tabular}{|c|c|c|c|}
\hline Variable & $\begin{array}{c}\text { Walking } \\
\text { independence } \\
(n=67)\end{array}$ & $\begin{array}{c}\text { Walking } \\
\text { dependence } \\
(n=128)\end{array}$ & $P$-value \\
\hline \multicolumn{4}{|l|}{ Stroke subtype } \\
\hline Cerebral infarction & 34 & 82 & 0.091 \\
\hline Cerebral hemorrhage & 33 & 46 & \\
\hline \multicolumn{4}{|l|}{ Cerebral infarction subtype } \\
\hline Lacunar infarction & 3 & 11 & 0.388 \\
\hline Atherothrombotic infarction & 20 & 38 & 0.900 \\
\hline Cardioembolic infarction & 7 & 20 & 0.387 \\
\hline Others & 4 & 13 & 0.427 \\
\hline \multicolumn{4}{|l|}{ Cerebral hemorrhage subtype } \\
\hline Putaminal & 15 & 21 & 0.427 \\
\hline Thalamic & 7 & 16 & 0.816 \\
\hline Pontine & 0 & 0 & 0.117 \\
\hline Subcortical & 11 & 9 & 0.192 \\
\hline \multicolumn{4}{|l|}{ Higher brain dysfunction } \\
\hline Presence & 23 & 51 & 0.171 \\
\hline Absence & 44 & 77 & \\
\hline \multicolumn{4}{|l|}{ Modified Rankin Scale } \\
\hline Before onset & $0.4 \pm 0.9$ & $1.0 \pm 1.3$ & 0.000 \\
\hline Admission & $3.7 \pm 0.6$ & $4.2 \pm 0.8$ & 0.000 \\
\hline Discharge & $2.4 \pm 1.0$ & $3.3 \pm 1.0$ & 0.000 \\
\hline \multicolumn{4}{|l|}{ Functional independence measure total score } \\
\hline Admission & $67.6 \pm 17.6$ & $50.7 \pm 20.6$ & 0.000 \\
\hline Discharge & $107.3 \pm 13.0$ & $77.5 \pm 26.6$ & 0.000 \\
\hline \multicolumn{4}{|c|}{ Functional independence measure motor score } \\
\hline Admission & $43.2 \pm 12.4$ & $31.3 \pm 14.9$ & 0.000 \\
\hline Discharge & $76.8 \pm 9.7$ & $54.0 \pm 20.8$ & 0.000 \\
\hline \multicolumn{4}{|c|}{ Functional independence measure-cognition score } \\
\hline Admission & $24.4 \pm 8.0$ & $19.4 \pm 7.8$ & 0.000 \\
\hline Discharge & $30.6 \pm 5.0$ & $23.5 \pm 7.4$ & 0.000 \\
\hline \multicolumn{4}{|c|}{ Functional independence measure walking score } \\
\hline Admission & $1.9 \pm 1.3$ & $1.4 \pm 0.9$ & 0.006 \\
\hline Discharge & $6.3 \pm 0.6$ & $2.7 \pm 1.7$ & 0.000 \\
\hline Physical therapy intervention (hr) & $140.8 \pm 41.7$ & $124.6 \pm 43.2$ & 0.012 \\
\hline Occupational therapy intervention (hr) & $128.9 \pm 40.7$ & $114.2 \pm 39.2$ & 0.015 \\
\hline Speech therapy intervention (hr) & $82.3 \pm 48.0$ & $91.7 \pm 41.2$ & 0.180 \\
\hline $\begin{array}{l}\text { Physical therapy and occupational } \\
\text { therapy intervention (hr) }\end{array}$ & $269.6 \pm 78.1$ & $238.8 \pm 80.7$ & 0.011 \\
\hline $\begin{array}{l}\text { Physical therapy intervention dose } \\
\text { delivered in } 1 \text { day (hr) }\end{array}$ & $1.1 \pm 0.2$ & $1.1 \pm 0.2$ & 0.011 \\
\hline $\begin{array}{l}\text { Occupational therapy intervention dose } \\
\text { delivered in } 1 \text { day (hr) }\end{array}$ & $1.0 \pm 0.1$ & $0.9 \pm 0.1$ & 0.001 \\
\hline $\begin{array}{l}\text { Speech therapy intervention dose } \\
\text { delivered in } 1 \text { day (hr) }\end{array}$ & $0.6 \pm 0.3$ & $0.7 \pm 0.3$ & 0.016 \\
\hline $\begin{array}{l}\text { Physical and occupational therapy } \\
\text { intervention dose delivered in } 1 \text { day (hr) }\end{array}$ & $2.1 \pm 0.3$ & $2.0 \pm 0.2$ & 0.000 \\
\hline
\end{tabular}

Values are presented as number or mean \pm standard deviation.

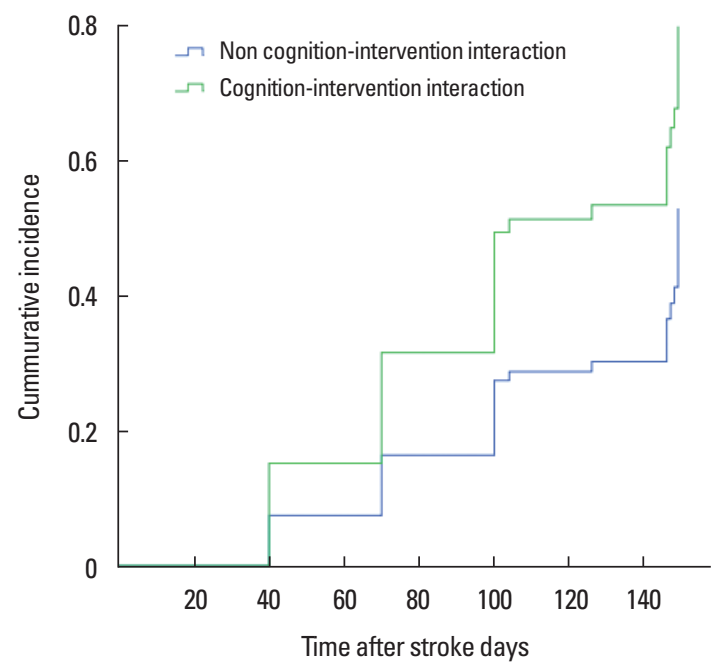

Fig. 2. Kaplan-Meier curve showing the cumulative incidence of walking independence with or without cognition-intervention interaction.

Table 2. Cox proportional hazards regression analysis of variables predicting walking independence

\begin{tabular}{lcccc}
\hline Independent variable & $\begin{array}{c}\text { Partial } \\
\text { regression } \\
\text { coefficient }\end{array}$ & $P$-value & $\begin{array}{c}\text { Hazard } \\
\text { ratio }\end{array}$ & $95 \% \mathrm{Cl}$ \\
\hline Age & -0.029 & 0.001 & 0.971 & $0.954-0.988$ \\
$\begin{array}{l}\text { Area of the affected cerebrum } \\
\text { (left vs. right) }\end{array}$ & -0.609 & 0.017 & 0.544 & $0.330-0.897$ \\
$\begin{array}{l}\text { Cognition-intervention interaction } \\
\text { Conn }\end{array}$ & 0.584 & 0.045 & 1.794 & $1.000-3.250$ \\
\hline
\end{tabular}

$\mathrm{Cl}$, confidence interval.

tional therapy intervention in 1 day, speech therapy intervention in 1 day, body mass index, functional independence measure-motor, functional independence measure-cognition, and cognitionintervention interaction. The results of Cox proportional hazards analysis revealed that age (hazard ratios $=0.971$ per 1 year), left versus right cerebral damage (hazard ratios $=0.544$ ), and cognition-intervention interaction (hazard ratios $=1.794$ ) significantly contributed to the model.

\section{DISCUSSION}

Factors related to the intervention in this study, such as the cognition-intervention interaction, influenced walking independence. The presence of a cognition-intervention interaction in this study meant that $\geq 2 \mathrm{hr}$ of physical therapy and occupational therapy and occupational physical therapy and occupational therapy intervention delivered in 1 day was more likely to be effective if functional independence measure-cognition was $\geq 20$. A previous 
study (Kwakkel et al., 1999) evaluating the amount of intervention reported that the activities of daily living of stroke patients with moderate or severe impairment improved after 3 months with increasing daily interventions early after stroke onset. These results are corroborated by systematic reviews (Kwakkel et al., 2004). Furthermore, many studies have reported that cognitive function affects walking (Beauchet et al., 2016; Block et al., 2016). Results of our study are consistent with those of Hiraoka et al. (2017); however, our findings do not imply that stroke patients with cognitive dysfunction show no improvements following intervention. This study has clarified the conditions that increase the likelihood of effect of a therapy intervention on walking independence.

The results of this study suggest that it is helpful to include age and location of cerebral damage (right or left) to predict walking independence. Many studies have reported that age influences the recovery of walking after stroke (Kugler et al., 2003). Other reported problems associated with aging are decline in cognitive function (Stolze et al., 2005) and decreased lower-limb function (Bassey et al., 1988). In addition, Hageman and Blanke (1986) have reported that walking independence declines and the gait speed rapidly decreases with age. The present study results can be considered similar to the findings above. Indeed, there was a significant difference in modified Rankin Scale before admission between those with walking independence and those with walking dependence. Although we did not evaluate lower-limb and cognitive functions before admission, the consideration of the above points implicitly suggests that these functions were poorer among patients with walking dependence. In other words, the effect of age on walking independence found in the present study was not greatly different from that reported in the previous studies.

This finding that the damaged area of the cerebrum (right or left) influenced walking independence may be explained by the characteristics of the affected area. These results suggested that stroke patients with left cerebral damage were less likely to recover walking independence than those with right cerebral damage. In general, the left cerebrum is involved in activities such as processing and understanding languages or symbols, logical thinking, and analyzing or ordering information. Conversely, the right cerebrum is involved in sensory functions such as painting, recognizing shapes, listening to music, intuition, art, and creativity, and it simultaneously processes visual and spatial information as a whole. We observed that the majority of left cerebral damage resulted in aphasia, which was categorized into motor and sensory aphasia. Sensory aphasia might have affected walking independence because it implies low ability to listen and understand lan- guage. It is reasonable to consider that physical therapy intervention, especially the explanation using language, becomes difficult to accept for people who have sensory aphasia. However, the relationship between sensory aphasia and walking independence has not been reported to our knowledge. Only one study has reported that left cerebral injury reduces activities of daily living capability compared with right cerebral injury (Gardarsdóttir aad Kaplan, 2002). Stroke patients who did not achieve walking independence in the present study had lower activities of daily living capability; thus, speech therapy intervention for management of aphasia might be more helpful. In summary, the relationship between left cerebral damage and walking independence may be attributable to higher brain dysfunction, primarily consisting of sensory aphasia.

This study has some limitations. First, we were impossible to identify the detailed characteristics of brain damage and to consider the extent of physical dysfunction or higher brain dysfunction. Design of this study was a retrospective cohort study, and we were unable to assess the site of cerebral vascular infarction and hemorrhage, as well as the extent of motor paralysis and muscle strength. Furthermore, the extent and content of higher brain dysfunction could not be investigated. Further studies that stratify patients based on the site of brain injury and the degree of physical or higher brain dysfunction are needed to examine the influence of amount of interventions. The second limitation was the variation in the intervention program received during the recovery phase by each patient. Clinically, therapists customized each program according to the condition of the stroke patient. Therefore, the intervention received by study participants was probably not uniform. In future, it is necessary to take into account the content of therapy for determining walking independence. The third limitation is related to the threshold of the cognition-intervention interaction, which was based on the median scores for variables reflecting cognitive function and intervention. Using continuous data might enable a more detailed analysis. Despite limitations of this study, we believe that the conclusions are valid because this study had a sufficient sample size and functional independence measure of walking independence was determined by multiple nurses. Thus, this study emphasizes the relevance of a cognition-intervention interaction on walking independence of stroke patients.

This study investigated the factors affecting walking independence at discharge in stroke patients admitted to a rehabilitation ward during the recovery period. Cox proportional hazards analysis revealed that age, location of cerebral injury site (right or left), 
and cognitive-intervention interaction on admission were significant predictors of walking independence. Walking independence was more likely to be achieved with intervention among stroke patients with high cognitive function. That is, the conditions that increase the likelihood of an effect of therapy intervention on walking independence were identified in this study.

\section{CONFLICT OF INTEREST}

No potential conflict of interest relevant to this article was reported.

\section{REFERENCES}

Bassey EJ, Bendall MJ, Pearson M. Muscle strength in the triceps surae and objectively measured customary walking activity in men and women over 65 years of age. Clin Sci (Lond) 1988;74:85-89.

Beauchet O, Annweiler C, Callisaya ML, De Cock AM, Helbostad JL, Kressig RW, Srikanth V, Steinmetz JP, Blumen HM, Verghese J, Allali G. Poor gait performance and prediction of dementia: results from a meta-analysis. J Am Med Dir Assoc 2016;17:482-490.

Block VA, Pitsch E, Tahir P, Cree BA, Allen DD, Gelfand JM. Remote physical activity monitoring in neurological disease: a systematic review. PLoS One 2016;11:e0154335.

Duarte E, Marco E, Muniesa JM, Belmonte R, Aguilar JJ, Escalada F. Early detection of non-ambulatory survivors six months after stroke. NeuroRehabilitation 2010;26:317-323.

Gardarsdóttir S, Kaplan S. Validity of the Arnadóttir OT-ADL Neurobehavioral Evaluation (A-ONE): performance in activities of daily living and neurobehavioral impairments of persons with left and right hemisphere damage. Am J Occup Ther 2002;56:499-508.

Hageman PA, Blanke DJ. Comparison of gait of young women and elderly women. Phys Ther 1986;66:1382-1387.

Hiraoka S, Maeshima S, Okazaki H, Hori H, Tanaka S, Okamoto S, Funahashi R, Yagihashi K, Fuse I, Asano N, Sonoda S. Factors necessary for independent walking in patients with thalamic hemorrhage. BMC Neurol 2017;17:211.

Jørgensen HS, Nakayama H, Raaschou HO, Olsen TS. Recovery of walking function in stroke patients: the Copenhagen Stroke Study. Arch Phys Med Rehabil 1995;76:27-32.

Kugler C, Altenhöner T, Lochner P, Ferbert A; Hessian Stroke Data Bank Study Group ASH. Does age influence early recovery from ischemic stroke? A study from the Hessian Stroke Data Bank. J Neurol 2003; 250:676-681.

Kwakkel G, van Peppen R, Wagenaar RC, Wood Dauphinee S, Richards
C, Ashburn A, Miller K, Lincoln N, Partridge C, Wellwood I, Langhorne P. Effects of augmented exercise therapy time after stroke: a meta-analysis. Stroke 2004;35:2529-2539.

Kwakkel G, Wagenaar RC, Twisk JW, Lankhorst GJ, Koetsier JC. Intensity of leg and arm training after primary middle-cerebral-artery stroke: a randomised trial. Lancet 1999;354:191-196.

Mayo NE, Wood-Dauphinee S, Côté R, Durcan L, Carlton J. Activity, participation, and quality of life 6 months poststroke. Arch Phys Med Rehabil 2002;83:1035-1042.

Ministry of Health, Labor and Welfare. 2014 Patient survey overiew: the total number of patients of the main diseases [Internet]. Tokyo (Japan): Ministry of Health, Labor and Welfare; 2014a [cited 2018 Dec 5]. Available from: https://www.mhlw.go.jp/toukei/saikin/hw/kanja/14/.

Ministry of Health, Labor and Welfare. 2014 Patient survey overview: treatment rate [Internet]. Tokyo (Japan): Ministry of Health, Labor and Welfare; 2014b [cited 2018 Dec 5]. Available from: https://www. mhlw.go.jp/toukei/saikin/hw/kanja/14/.

Ministry of Health, Labor and Welfare. Care for the eldery in 2015- towards the establishment of care to support the dignity of the elderly [Internet]. Tokyo (Japan): Ministry of Health, Labor and Welfare; 2015 [cited 2018 Dec 5]. Available from: https://www.mhlw.go.jp/topics/kaigo/ kentou/15kourei/3.html

Mosselman MJ, Kruitwagen CL, Schuurmans MJ, Hafsteinsdóttir TB. Malnutrition and risk of malnutrition in patients with stroke: prevalence during hospital stay. J Neurosci Nurs 2013;45:194-204.

Mutai H, Furukawa T, Araki K, Misawa K, Hanihara T. Factors associated with functional recovery and home discharge in stroke patients admitted to a convalescent rehabilitation ward. Geriatr Gerontol Int 2012;12: 215-222.

Ozdemir F, Birtane M, Tabatabaei R, Kokino S, Ekuklu G. Comparing stroke rehabilitation outcomes between acute inpatient and nonintense home settings. Arch Phys Med Rehabil 2001;82:1375-1379.

Park SH, Sohn MK, Jee S, Yang SS. The Characteristics of cognitive impairment and their effects on functional outcome after inpatient rehabilitation in subacute stroke patients. Ann Rehabil Med 2017;41:734-742.

Patel AT, Duncan PW, Lai SM, Studenski S. The relation between impairments and functional outcomes poststroke. Arch Phys Med Rehabil 2000;81:1357-1363.

Sánchez-Blanco I, Ochoa-Sangrador C, López-Munaín L, Izquierdo-Sánchez M, Fermoso-Garcia J. Predictive model of functional independence in stroke patients admitted to a rehabilitation programme. Clin Rehabil 1999;13:464-475.

Shaughnessy M, Michael KM, Sorkin JD, Macko RF. Steps after stroke: capturing ambulatory recovery. Stroke 2005;36:1305-1307.

Stolze H, Klebe S, Baecker C, Zechlin C, Friege L, Pohle S, Deuschl G. 
Prevalence of gait disorders in hospitalized neurological patients. Mov Disord 2005;20:89-94.

Umehara T, Tanaka R, Tsunematsu M, Sugihara K, Moriuchi Y, Yata K, Muranaka K, Inoue J, Kohriyama T, Kakehashi M. Can the amount of interventions during the convalescent phase predict the achievement of independence in activities of daily living in patients with stroke? A Retrospective Cohort Study. J Stroke Cerebrovasc Dis 2018;27:24362444.

van Swieten JC, Koudstaal PJ, Visser MC, Schouten HJ, van Gijn J. Interob- server agreement for the assessment of handicap in stroke patients. Stroke 1988;19:604-607.

Veerbeek JM, Kwakkel G, van Wegen EE, Ket JC, Heymans MW. Early prediction of outcome of activities of daily living after stroke: a systematic review. Stroke 2011;42:1482-1488.

Yoshimoto Y, Kwak S. Age-related multifactorial causes of neurological deterioration after early surgery for aneurysmal subarachnoid hemorrhage. J Neurosurg 1995;83:984-988. 